\title{
Actos de habla egocéntricos y altrocéntricos y su relación con raza y clase social: un ejemplo en la obra literaria venezolana
}

\author{
Egocentric and Altrocentric Speech Acts and their Relationship with \\ Race and Social Class: An Example in Venezuelan Literature
} Atos de fala egocêntricos e altrocênctricos e sua relação com raça e
classe social: um exemplo da obra literária venezuelana

Carolina Gutiérrez-Rivas ${ }^{1}$

\section{Resumen}

La obra literaria es generadora de conocimiento sobre la lengua y de ella pueden extraerse datos sobre la actividad lingüística en todos sus niveles, incluyendo el pragmático-discursivo. Autores como Brown y Gilman (1989); Gancedo Ruiz (2016); Haverkate (2001); Zamora (2014), entre otros, han llevado a cabo análisis en textos narrativos de ficción. Este tipo de material es una fuente de datos accesibles y confiables para la observación de ciertos patrones lingüísticos, en comparación a los datos que puedan obtenerse de la lengua hablada, cuyo tiempo de recolección resulta poco práctico. Por tanto, el corpus de este trabaj o de investigación es la novela venezolana Ana Isabel, una niña decente, de Antonia Palacios (1949), y se centra en el análisis de aspectos sociopragmáticos, tales como la manifestación de las variables de raza y clase social a través de actos de habla representativos y directivos. Asimismo, empleando la Teoría de la Cortesía (Brown y Levinson, 1987) y los conceptos delineados por Haverkate (2001) se busca definir si estos actos de habla son egocéntricos o altrocéntricos. Por último, se examina el papel de la mitigación en ambos casos. Se verá que, en su mayoría, se hallaron actos habla egocéntricos sin mitigación, lo cual difiere de lo propuesto por Haverkate (2001) en cuanto a la mitigación como acompañante del acto de habla egocéntrico.

\section{Palabras clave}

actos de habla; egocéntrico; altrocéntrico; mitigación; imagen

\section{Abstract}

Literary works are generators of knowledge about language since they can provide valuable data on linguistic activity at all levels, including the discourse-pragmatic one. Authors such as Brown and Gilman (1989), Gancedo Ruiz (2016), Haverkate (2001) and Zamora (2014), have analyzed fictional narrative texts. This is because such material is an accessible and reliable source of linguistic information as compared to oral language, where it proves to be impractical, in terms of the time required to observe certain linguistic patterns. The corpus of this research study is the Venezuelan novel Ana Isabel, una niña decente, by Antonia Palacios (1949). The analysis focuses on sociopragmatic aspects, such as the manifestation of race and social class in performative and directive speech acts. Politeness Theory (Brown \& Levinson, 1987) is also applied, along with Haverkate's (2001) concepts of egocentric and altrocentric speech acts. Also, the role of mitigation is examined in both cases. The analysis reveals that, for the most part, the speech acts found in the novel are egocentric without mitigation, which contradicts Haverkate's idea of mitigation as a companion to the egocentric speech act.

Keywords

speech acts; egocentric; altrocentric; mitigation; face

1 Doctora en Lingüística Hispánica de The University of Florida. Actualmente es profesora asociada en Central Michigan University. Correo electrónico: gutie1c@cmich.edu 


\section{Resumo}

A obra literária gera conhecimento sobre a língua e de ela é possível extrair dados sobre a atividade linguística em todos seus níveis, inclusive o pragmático-discursivo. Autores como Brown e Gilman (1989); Gancedo Ruiz (2016); Haverkate (2011); Zamora (2014), entre outros, realizaram análises em textos narrativos de ficção. Este tipo de material é uma fonte de dados acessíveis e confiáveis para a observação de alguns padrões linguísticos, em comparação aos dados que podem ser obtidos da língua falada, cujo tempo de coleta é pouco prático. Portanto, o corpus desde trabalho de pesquisa é o romance venezuelano Ana Isabel, una niña decente, de Antonia Palacios (1949), e está centrado na análise de aspectos sociopragmáticos como a manifestação das variáveis de raça e classe social através de atos de fala representativos e diretivos. Assim mesmo, utilizando a Teoria da Cortesia (Brown \& Levinson, 1987) e os conceitos esboçados por Haverkate (2001), procura-se definir se esses atos de fala são egocêntricos ou altrocêntricos. Por último, examina-se o papel da mitigação nos dois casos. Maioritariamente, encontraram-se atos de fala egocêntricos sem mitigação, o que difere do pressuposto por Haverkate com relação à mitigação como acompanhante do ato de fala egocêntrico.

\section{Palavras chave}

atos de fala; egocêntrico; altrocêntrico: mitigação; imagem

\section{Artículo recibido el 31 de enero de 2017 y aprobado el 28 de julio de 2017}

\section{Introducción}

La obra literaria es, sin duda, gran generadora de conocimiento sobre la lengua y de ella se pueden extraer valiosos datos sobre la actividad lingüística a todo nivel, incluyendo el pragmático-discursivo. En palabras de Zamora (2014), la principal razón de emplear textos narrativos es porque proporcionan, a través de la voz del narrador y los personajes a los que este dota de voz propia, "un acercamiento a realidades difícilmente observables con las técnicas de obtención de datos que no sean el método etnográfico de la observación participante del investigador inserto en la comunidad que quiere estudiar" (p. 79). Es así como, en un intento por identificar y describir los tipos de actos de habla, definir si son egocéntricos o altrocéntricos, y determinar su incidencia en la manifestación de clase social y raza en una pieza clave de la literatura venezolana, este trabajo toma como corpus principal la novela de la escritora venezolana Antonia Palacios: Ana Isabel, una niña decente (1949). Si se parte del principio de que la literatura es ficción y, a la vez, producto de la realidad que se cierne en torno a ella, esta investigación se apoya en que "las producciones literarias pueden verse como productos de sus contextos sociales" (Schmid, 2015, p. 2) y pueden, entonces, proporcionar información sustancial acerca de costumbres, modas, creencias, usanzas y giros lingüísticos. Asimismo, estudios de esta naturaleza han sido propuestos como herramienta pedagógica, que permitiría a aprendices de una lengua extranjera saber elegir qué decir o qué escribir en situaciones particulares de acuerdo a principios sociales abstractos (cf. Castañeda Castañeda, 2010). En el caso de este trabajo, se estaría haciendo una pequeña contribución al acervo de estudios pedagógicos al mostrar entornos sociales históricos a los que los aprendices de español como lengua extranjera tienen escaso o ningún acceso.

La novela que se analiza transcurre en Caracas durante la primera mitad del siglo xx. En ella se presenta la vida de una niña de ocho años, Ana Isabel Alcántara, a través de un(a) narrador(a) omnipresente cuya voz se confunde y enmascara, por momentos, con la de Ana Isabel. El libro de Palacios ha sido estudiado desde diversos ángulos. Para Rivas (2010), se trata de la

... memoria de una infancia citadina, encerrada en los prejuicios de una sociedad aún pueblerina, donde las mujeres solo tenían algún espacio de libertad en la plaza durante la infancia y quedaban enclaustradas en el espacio doméstico al despuntar la adolescencia. (Rivas, 2010, pp. 210-211).

Asimismo, Nichols (2013) analiza la obra desde el punto de vista de la formación de identidad y nación con relación al control de la sexualidad y el cuerpo femenino. Bravo (2008, parr. 3) propone que la novela hace patente la pérdida de la infancia y del paso a la adolescencia. El autor deposita la intencionalidad de 
la novela en "narrar el acontecimiento de la vida, ese viaje esencial, a la vez como continua pérdida y como constitución del yo: plenitud de un estado (la infancia) y adquisición de la conciencia para la posibilidad del conocimiento". Schmid (2015) emplea la teoría marxista para revelar los conceptos de clase y estatus social presentes en la novela y su incidencia en la vida de la niña protagonista. El autor señala que la novela "ilustra la transición a un sistema capitalista" (p. 1) que recién comenzaba a formarse en la Venezuela de los años cuarenta.

Como se ve, aparte de lo femenino y la infancia perdida, la trama también ofrece una mirada cercana de otros problemas sociales del momento. Las variables de raza y clase social tienen un lugar preponderante en el discurso de los personajes. Desde las primeras páginas se empieza a conocer la verdadera situación de la protagonista, quien es hija de una familia que alguna vez fuera de alcurnia, pero que, por circunstancias no muy claras, quizás por la enfermedad del padre, se ha venido a menos. Parte del título, "una niña decente", sugiere que la familia sigue siendo "gente de bien", es decir, gente que, a pesar de las precariedades económicas, se considera a sí misma como de un estatus social superior. Este es el leitmotiv de una obra en la cual abundan actos de habla por los que se entretejen la imagen de la protagonista y los distintos interlocutores con las variables de raza y clase social (que, como se verá, no siempre van en directa covariación).

A partir de la visión confusa y ambigua que tienen los padres de Isabel (sobre todo la madre) se construyen los diálogos en los que se concibe la pobreza del otro como una abominación, y la pobreza de los Alcántara (apellido de la familia) como una virtud. La raza también se evidencia de varias maneras, esta vez no solo en la voz de la madre, sino además en la de la servidumbre.

Este estudio halla eco en la afirmación de Hernández-Flores (2008) según la cual

... la cortesía y las actividades de imagen en general son fenómenos que deben ser descritos específicamente de acuerdo con los contextos en que aparecen a fin de dar cuenta de las estrategias usadas, su función y sus consecuencias sociales y comunicativas en la interacción. (p. 681).

En estas páginas se plantea un nuevo enfoque hacia la novela de Palacios, esta vez desde la observación y análisis de aspectos sociopragmáticos, tales como la interacción entre las variables extralingüísticas de raza y clase social, y su manifestación a través de los actos de habla representativos y directivos. Del mismo modo, se presta particular atención a cómo los personajes (des)favorecen su propia imagen o la de Ana Isabel por medio de actos de habla altrocéntricos (los que protegen la imagen del oyente) y egocéntricos (los que protegen la imagen del hablante). Se intenta mostrar que estos últimos sirven, en la mayoría de los casos, como elementos aleccionadores para la protagonista, quien ante todo debe recordar que se trata de una niña decente.

\section{Raza y clase social en Venezuela}

Beals (1953), quien realiza un extenso recuento histórico sobre la formación de clases sociales en distintos países de América Latina, afirma que las sociedades latinoamericanas se moldearon cuando ideas e instituciones feudales aún tenían mucha fuerza en España y Portugal. Por esta razón, la Iglesia establecida en Latinoamérica fue, esencialmente de carácter pre-Reforma y permaneció aislada, en gran medida, de los cambios que sucedieron en Europa. Las líneas de clase estaban claramente demarcadas y tendieron a definirse, en parte, por la raza. La Venezuela de los años cincuenta, según la investigación de Beals (publicada apenas una década después de la novela en cuestión), presentaba una vasta diferencia porcentual en cuanto a su población indígena en comparación con países como Ecuador o Guatemala, y la población negra estaba confinada a la costa, a diferencia de países como Haití. Sin embargo, en la actualidad, la población que se reconoce a sí misma como afrodescendiente, un total de 181157 venezolanos, está distribuida en todo el territorio nacional; por ejemplo, más de 15000 afrodescendientes se encuentran en el estado Zulia, 18675 en el Distrito Capital, 3369 en 
el estado Monagas, 6364 en Vargas, 6070 en Falcón, 5600 en Lara, 5516 en Bolívar y 5334 en Anzoátegui (cf. Correo del Orinoco). Según estos datos, la población que se autodenomina puramente como afrovenezolana parece no ser un grupo muy nutrido. Sin embargo, debe considerarse el hecho de que este censo simplemente tiene en cuenta la categoría con la que los individuos se identifican, la cual tiende a ser, en gran parte de los casos, subjetiva. Es de subrayar que, en Venezuela, los rasgos físicos (como la forma de la nariz, por ejemplo) asociados con sangre mestiza se consideran feos y deformes (Gulbas, 2008). Si esto es así, no cabe duda de que autodefinirse solo como afrodescendiente porta, implícitamente, cierto estigma y habrá los que no quieran afrontar las consecuencias ${ }^{2}$.

Ya para finales del siglo XIX, académicos venezolanos como Laureano Vallenilla Lanz y José Gil Fortoul argüían que el largo proceso de mezcla de razas había acabado con toda traza de identidad africana e indígena y había descartado todo impulso negativo de las razas indeseadas. Consideraban la sangre blanca tan superior, que siglos de su influencia serían capaces de cancelar los efectos de la sangre indeseable ( $c f$. Nichols y Morse, 2010). No se ha de olvidar que, para el momento en que tiene lugar la novela, existía un sentido de nacionalismo que procuraba mantener la pureza de la sangre europea a la vez que rechazaba la identidad española (Nichols, 2013):

Puesto que las diferencias raciales quedaron descartadas $[\ldots]$ permanecía, entonces, el problema de clases. Pensadores positivistas como Gil Fortoul opinaban que la línea decisoria entre decente e indecente, bueno y malo, y civilizado e incivilizado se hallaba entre los pobres y los ricos [...] Este

2 Tal como apuntan Bolívar et al. (2007), para el momento de su investigación, el censo nacional no solicitaba a los venezolanos información sobre raza, color de piel o ubicación en un grupo étnico. Los indígenas que vivían en comunidades urbanas eran censados como parte de la comunidad y los que habitan en condiciones selváticas reciben un empadronamiento aparte. Sin embargo, durante el último censo se incluyó una pregunta que instaba a los encuestados a identificarse con una de las siguientes categorías: negro, afrodescendiente, moreno, blanco, otro (cf. Instituto Nacional de Estadística). pequeño dato histórico ayuda a ilustrar el nexo entre la supuesta decencia, la raza y la riqueza asociadas con la clase social. (p. 174, mi traducción).

Vale destacar que si bien en Venezuela, en el imaginario colectivo sobre lo social, clase y raza van de la mano, este vínculo logra desdibujarse si el estatus socioeconómico es alto. La intricada interrelación entre raza y clase social queda bastante clara en lo que comentan Bolívar et al. (2007, p. 376):

En Venezuela, como en muchas sociedades de América Latina, se produce una asimilación entre la estructura de las clases sociales y la distribución poblacional de los grupos étnicos que tiende a mostrar una coincidencia entre clase y raza: los ricos tienden a ser blancos y los oscuros de piel, pobres; pero los blancos no son todos ricos, ni tampoco los mestizos son todos pobres. Esta identificación clase-raza tiene en general muchas limitaciones [...].

La manera en que Palacios consigue desengranar ambas variables es magistral, y lo obtiene a través de personajes como los de Luisa Figueroa y Teresita, quienes evidencian esta imprecisión en la supuesta correlación según la cual raza blanca equivale a clase alta y raza no blanca equivale a clase baja. La primera niña es "trigueña, muy trigueña, ¡casi negra! [...] pero es rica" (Palacios, 1949, p. 85), y este hecho automáticamente la vuelve "decente". La segunda, Carmencita, es una niña blanca pero pobre, con la que Ana Isabel y sus amiguitas juegan en la plaza, pero "no se sabe quién es su mamá ni su papá" (p. 114), cuando en realidad se sabe que su madre murió y su padre es Ruperto, el carbonero. Lo expresado en la novela coincide con una investigación llevada a cabo en Caracas en el año 2008 por Gulbas, quien empleó la técnica de selección denominada pile-sorting technique, útil para "desarrollar un modelo cognitivo para la clasificación racial” (p. 227, mi traducción). La investigadora encontró que la identificación de raza no dependía únicamente del color de la piel, sino del estatus social y los rasgos físicos específicos, como la nariz y el pelo. Igualmente, la tendencia en las mujeres contemporáneas (que puede tomarse como 
el reflejo del imaginario tradicional venezolano) es a asociar la piel blanca con la superioridad.

La novela se desarrolla en una época de mucha inestabilidad política, económica y social, por lo que la democracia no había dado paso aún a lo que Capriles (2011, parra 3) llama "ilusión de armonía". Esta sensación contribuyó a forjar pertenencia cultural dentro de un esquema de homogeneización racial y democratización de las oportunidades.

\section{Trabajos previos sobre actos de habla y cortesía en la obra literaria}

Sobra decir que no es esta la primera tentativa de analizar un texto literario a la luz de una teoría pragmática, pero es de destacar que han sido pocas las investigaciones de este estilo. La razón puede hallarse, según Gancedo Ruiz (2016), en dos grandes argumentos que se han levantado en contra del empleo de la literatura como corpus de análisis pragmático: "la fictivización y la voluntad estética de la lengua literaria” (p. 165). Sin embargo, concuerdo con el parecer de la autora en que ambos argumentos pueden ser refutados gracias a investigaciones como las de Pratt (1977, citada en Gancedo Ruiz, 2016), quien defendió que cada acto de habla presente en una obra no se diferenciaría ni estructural ni funcionalmente de los encontrados en la vida diaria. Afirma Gancedo Ruiz que los actos de habla que llevan a cabo personajes de ficción no son falsos, sino que son del todo válidos. Basada en autores como Iñarrea de las Heras (1998, citado en Gancedo Ruiz, 2016) insiste en que los personajes respetan el esquema básico de comunicación, con la única diferencia de que oyente y hablante son ficticios.

A continuación se presenta un pequeño recuento cronológico de las obras académicas que han aplicado la teoría de la cortesía a la obra literaria, tanto en inglés como en español, en sus distintas variedades. Se ha de advertir que el corpus es, sin duda alguna, limitado, puesto que se han seleccionado solo trabajos afines y relevantes para la presente investigación.
Por ejemplo, aduciendo que los textos dramáticos proveen la mejor información sobre el habla coloquial de un periodo, y que representan toda la gama de aspectos de una sociedad en un periodo dado y, por tanto, son de gran relevancia para la teoría de la cortesía, Brown y Gilman (1989) se encargaron de examinar las dimensiones en las que contrastan las variables de poder $(\mathrm{P})$, distancia $(\mathrm{D})$ y ranking (o peso) (R) en cuatro obras de Shakespeare: Hamlet, King Lear, Macbeth y Otelo. El hallazgo más prominente de su trabajo es que, mientras poder $(\mathrm{P}) \mathrm{y}$ peso $(\mathrm{R})$ concuerdan con lo que propone la teoría, la variable distancia (D), no. Según los autores, los dos componentes de (D), cercanía interactiva y afecto, no están estrechamente relacionados en las obras. El afecto tiene una fuerte influencia en la cortesía: a mayor afinidad, mayor cortesía y a menor afinidad, menor cortesía; y la cercanía interactiva tiene poco o ningún efecto en la cortesía.

A su vez, e inspirado en las observaciones de Brown y Gilman (1989), Haverkate (2001) lleva a cabo un análisis empírico similar en los diálogos del Quijote, en el que se centra en actos realizativos y expresivos, la estructura argumentativa de los diálogos y la representación de la imagen negativa de los protagonistas. Es de suma relevancia dejar claro que, para Haverkate, la teoría de la cortesía verbal (Brown y Levinson, 1987) es un marco de referencia original para analizar la personalidad y la interacción social de los protagonistas de la obra literaria. El autor señala que "no es aventurado suponer que estos diálogos suministran una considerable cantidad de información sobre el español coloquial de la época" (Haverkate, 2001, p. 129). En su análisis, el autor emplea los conceptos de actos de habla egocéntricos y altrocéntricos, de los cuales se nutre también esta investigación y que serán ampliados más adelante.

Siguiendo el orden cronológico, otro estudio de relevancia es el realizado por Álvarez y Valeri (2005), sobre imagen y cortesía en la novela Ifigenia, de la escritora venezolana Teresa de la Parra. El análisis tiene en cuenta la teoría de la cortesía de Brown y Levinson (1987), el concepto de imagen de Goffman 
(1967) y los procedimientos del análisis crítico del discurso propuestos por van Dijk (1998) y Fairclough (1995). Las autoras concluyen que, a la luz de una lectura analítica de la novela, es posible conocer las normas que regían a la clase dominante de la sociedad caraqueña de principios del siglo xx. Además, insisten en que dichas normas no son simplemente un código de buena conducta, sino que deben ser entendidas "como un valor cultural en la clase distinguida de la sociedad de ese entonces que se emplea para construir una sociedad autoritaria, donde las clases sociales están separadas y los géneros claramente diferenciados" (Álvarez y Valeri, 2005, p. 24).

En 2010, Castañeda Castañeda llevó a cabo un análisis cuyos objetivos eran examinar las estrategias de cortesía positiva empleadas por los narradores en textos literarios escritos en inglés ${ }^{3}$ para determinar en qué medida el narrador propicia la participación del lector. La autora, quien pone especial énfasis en los vocativos que reflejan la actitud del narrador frente al lector, concluye que existen evidencias lingüísticas en los textos que permiten determinar si los narradores aplicaron estrategias para reconocer la imagen positiva del lector, y el efecto de estas sobre la reacción del lector frente al contenido del texto. Asimismo, señala la investigadora que las estrategias de cortesía positiva no son tan frecuentes, sino que "las amenazas a la imagen positiva del interlocutor son más comunes que el uso explícito de estrategias de cortesía positiva" (p. 14).

En el trabajo de Vallejo Zapata (2011), se muestra un análisis pragmalingüístico del reproche y el silencio en la obra teatral Diatriba de amor contra un hombre sentado, de Gabriel García Márquez, empleando los modelos de la teoría de la cortesía y el análisis conversacional. El reproche fue estudiado desde el nivel de amenaza a la imagen, tanto positiva como negativa, desde la perspectiva teórica de Brown y Levinson. En cuanto al silencio, este se observa a partir de dos instancias: (1) los lugares pertinentes a la transición (LPT), o momentos conversacionales donde resulta pertinente un cambio de turno, propuestos original-

3 Véase Castañeda Castañeda (2010) para un inventario completo de los textos que analiza. mente por Sacks, Schegloff y Jefferson (1978); y (2) los movimientos, o la unidad mínima del turno conversacional, de acuerdo al modelo de Owen (1981). El autor concluye que el reproche es un acto de habla que atenta simultáneamente contra ambas imágenes, y afirma que el silencio funge como acto de habla indirecto que encierra una segunda fuerza ilocutiva: "la del estado psicológico del hablante o su valoración acerca de la proposición” (Vallejo Zapata, 2011, p. 62). Es interesante destacar que, según el investigador, el silencio, ya sea como pausa o como silencio elocuente, carece de contenido proposicional, pero es posible determinar su intención y significado si existe algún índice no verbal (proxémico, kinésico, gestual).

Bidot Martínez y Vargas Arias (2012) se plantearon los objetivos de describir el insulto desde el punto de vista formal y funcional como estrategia descortés en los personajes de la obra Aire frío, del escritor Virgilio Piñera. El propósito fue mostrar la relación existente entre el uso del insulto y el condicionamiento socioeconómico a partir de una clasificación del insulto como muy amenazante, amenazante, poco amenazante y nada amenazante. Las autoras concluyen que "todas estas expresiones y maneras de insultar están latentes en el habla del cubano de hoy, quizás con nuevas innovaciones en el léxico; mayor violencia verbal o nuevos matices" (Bidot Martínez y Vargas Arias, 2012, p. 31).

En cuanto a estudios sociolingüísticos en la obra literaria, se halla el de Flores Ohlson (2014), quien se encarga de inventariar y analizar fenómenos del habla en las protagonistas de la novela Diez mujeres, de Marcela Serrano. La investigadora se concentra en todo tipo de expresiones regionales, vulgares, malsonantes y coloquiales, apelativos e interjecciones, adjetivos, adverbios, y prefijos, así como en la densidad léxica, los diminutivos, el voseo, entre otros, que usa la autora de la novela para caracterizar a los personajes según su clase social. Así, los personajes de clase socioeconómica baja usarán más voseo verbal, apócopes y diminutivos, mientras que las de clase socioeconómica alta recurrirán más al uso del inglés, referencias a escritores, pintores y músicos, por ejemplo. 
Posteriormente, vale la pena reseñar el trabajo de Zamora (2014), en el cual se estudian textos narrativos de ficción y no ficción. Para estudiar las actividades de imagen de los interlocutores de sus obras, el autor también se basa, principalmente, en los conceptos de Goffman (1967) y Brown y Levinson (1987). A lo largo de su análisis, Zamora (2014) logra exhibir varios aspectos pragmáticos presentes en los textos seleccionados, como, por ejemplo, la relación diádica asimétrica basada en la diferencia del estatus en el texto de no ficción; y la reconstrucción de los mecanismos de intercambio de turnos y de la caracterización de los enunciados en el paso de la oralidad a la escritura. El autor es claro al señalar que este tipo de material resulta una alternativa asequible, en comparación con la obtención de datos transcritos procedentes de material grabado en conversaciones reales, sobre todo en circunstancias en las que resulta problemática la obtención de datos de la lengua hablada.

Por último, se debe incluir en esta lista el estudio de Gancedo Ruiz (2016), quien tiene la intención de justificar el empleo de obras literarias como corpus válido para caracterizar aspectos de imagen sociocultural en la comunidad española. La autora defiende el empleo del texto literario dramático como herramienta para estudiar fenómenos pragmáticos desde una perspectiva histórica. Sus principales ejemplos provienen de $E l$ sí de las niñas, de Fernández de Moratín, y de Bajarse al moro de Alonso de Santos.

No hay duda de que todos los investigadores mencionados en este apartado consideran la obra literaria como una importante fuente de datos viables para el análisis lingüístico. En especial Zamora (2014) enfatiza el hecho de que

... no podemos descartar, por juzgarlo de escasa relevancia frente a la investigación de la lengua hablada, el uso de material narrativo procedente de la lengua literaria en los estudios de pragmática y de análisis del discurso, y especialmente en los estudios relacionados con las actividades de imagen en la comunicación humana.

\section{Marco teórico}

\section{La teoría de los actos de habla}

El presente estudio se sustenta teóricamente en una combinación de la teoría de los actos de habla, de Austin (1962) y Searle $(1969,1976)$, con la teoría de la cortesía de Brown y Levinson (1987). Asimismo, al efectuar el análisis se aplican los conceptos de actos de habla egocéntricos y altrocéntricos de Haverkate (2001) a los ejemplos encontrados.

La teoría de los actos de habla se origina en la tradición británica iniciada por Austin (1962) y continuada por colaboradores cercanos, como Searle $(1969,1976)$. Según Austin, "decir algo es hacer algo" (1962, p. 12, mi traducción, énfasis del original). Asimismo, otros lingüistas y filósofos del lenguaje definieron y clasificaron el acto de habla como una unidad especial, que representa "un nivel distinto al de la oración, y no identificable con ninguna porción de otros niveles gramaticales, ni con segmentos de ningún tamaño particular definido en términos de otros niveles dentro de la gramática" (Gumperz y Hymes 1972, p. 57, mi traducción). Por su parte, Searle ([1969] 1994), quien encuentra deficiente la teoría de Austin y decide perfeccionarla ( $c f$. Mey, 2001 ), define los actos de habla como: "las unidades básicas o mínimas de la comunicación lingüística" (Searle, p. 26). Al hacer la reclasificación de los actos de habla, Searle (1976) decide nombrarlos y explicarlos de la siguiente forma ${ }^{4}$ :

- Representativos: comprometen al hablante con la verdad de la proposición expresada (ej.: acertar o concluir).

4 Los actos de habla poseen un efecto locutivo (por ejemplo: si un hablante dice la frase "hace frío" sin implicar amenaza, promesa o deseo de que algo cambie a su alrededor, está emitiendo un acto de habla locutivo). Si el hablante produce dicho acto de habla con intenciones de obtener algo de su(s) interlocutor(es), se dice que el acto de habla acarrea fuerza ilocutiva. Existe fuerza ilocutiva en un acto de habla como "hace frío" si el hablante tiene la intención de que alguien le preste un abrigo, por ejemplo, al decir estas palabras. Por último, el acto de habla tendrá un efecto perlocutivo si el hablante logra que su interlocutor le ayude a conseguir su objetivo, en este caso, prestarle un abrigo. 
- Directivos: son intentos del hablante para hacer que el oyente haga algo (ej.: peticiones, etc.).

- Compromisorios: comprometen al hablante a realizar acciones en un futuro (ej.: promesas, amenazas, etc.).

- Expresivos: expresan un estado psicológico (ej.: disculpas, agradecimientos, etc.).

- Declaraciones: efectúan cambios inmediatos en el estado actual de las cosas y tienden a elaborarse en instituciones extralingüísticas (ej.: declaraciones de guerra, despidos de un empleo, etc.)

Explica Searle que la unidad lingüística de la comunicación no es, como se pensaba en años anteriores, el símbolo, la palabra o la oración, sino la producción de todos ellos combinados en la emisión de un acto de habla, el cual puede tener forma de afirmación o pregunta y usarse para dar instrucciones, pedir cosas, dar las gracias, etc. Una diferencia consiste en que de los sonidos o trazos que una persona hace al realizar un acto ilocucionario se dice característicamente que tienen significado, y una segunda diferencia, relacionada con la anterior, consiste en que se dice característicamente que una persona quiere decir algo mediante esos sonidos o trazos. Dicho en palabras de Searle ([1969] 1994): "Característicamente, cuando se habla se quiere decir algo mediante lo que se dice, y de lo que se dice, de la sarta de morfemas que se emite, se dice característicamente que tiene un significado" (p. 51).

Uno de los criterios que propone Searle, y que difiere de los de Austin, es el estado psicológico expresado del hablante: una "creencia" se puede expresar como una afirmación, una aseveración, una observación, etc. ( $c f$. Mey, 2001). Con relación al estado psicológico del hablante, menciona Haverkate (2001) que los actos de habla (o actos comunicativos) se pueden dividir en egocéntricos y altrocéntricos:
[Los egocéntricos] tienen por objeto proteger y fortalecer la imagen positiva del hablante, [...] [los altrocéntricos] la del oyente. Como la función básica de la cortesía se interpreta comúnmente en términos del beneficio del interlocutor, la categoría egocéntrica ha atraído poca atención en la lingüística pragmática. No obstante juega un papel primordial en la interacción verbal cotidiana, puesto que los participantes en un diálogo suelen esforzarse por conseguir una posición central en el universo del discurso referido. (p. 131).

El autor aclara, además, que el fomento egocéntrico de la imagen positiva podría calificarse de "autocortesía". A lo largo de la novela, se identificarán y clasificarán aquellos actos de habla que hagan mención a la raza y la clase social y se analizará si son egocéntricos o altrocéntricos.

\section{La teoría de la cortesía}

La relación entre los actos de habla y la imagen se hace evidente al determinar qué tipo de imagen se intenta (des)favorecer en el momento de la emisión del acto de habla. Brown y Levinson (1987) describen las reglas de la cortesía en términos de "imagen positiva" e "imagen negativa". Lo que los autores llaman imagen, y lo relativo a protegerla frente a otro(s), tiene que ver con la conocida expresión inglesa saving face ("salvaguardar la imagen"). Para ellos, la noción de imagen consiste en dos tipos de deseo atribuidos por los interactuantes entre sí: el deseo de que no le impidan realizar acciones (imagen negativa) y el deseo de que lo aprueben (imagen positiva). Entre muchos ejemplos, la teoría asevera que las expresiones de desaprobación, críticas y ridiculización, entre otros son "actos que muestran una evaluación negativa del hablante sobre algunos aspectos de la imagen positiva del oyente" (p. 66, mi traducción). Proponen, por tanto, que toda vez que se deba expresar un acto amenazador a la imagen pública (AAIP) (en inglés, Face Threatening Act) o una acción discursiva que imponga una amenaza a la imagen positiva o negativa del interlocutor, es necesario que el hablante emplee estrategias que mitiguen dicha amenaza. 
Al respecto, afirma Fraser (1980) que la mitigación es una estrategia utilizada para suavizar o reducir la fuerza del acto de habla, ya que sus efectos pueden no ser bien recibidos por el oyente. Asimismo, para Haverkate (2001) la mitigación es una "subestrategia de cortesía" (p. 135). Sin embargo, la hipótesis que intentaré probar a lo largo del análisis es que los actos de habla egocéntricos hallados en la novela, o aquellos destinados a satisfacer la imagen positiva del hablante, presentan poca mitigación, carecen de ella o presentan agraviamiento. El agraviamiento a la imagen se considera como descortés. Culpeper (2011) asegura que entre las tantas definiciones aportadas por varios autores acerca de la descortesía se encuentra la de Bousfield (2008), que bien podría explicar lo que ocurre en la novela:

\section{[...] la descortesía constituye la comunicación de} actos verbales amenazadores a la imagen pública (AAIP) que son intencionalmente gratuitos y conflictivos, y se emiten deliberadamente (1) sin mitigación, en contextos que requieren mitigación, y/o (2) con agresión premeditada, es decir, con una amenaza a la imagen "potenciada" o maximizada para, de alguna forma, aumentar el daño infligido a la imagen. (Culpeper, 2011, p. 20, mi traducción).

Se presume que la finalidad de emitir este tipo de actos descorteses sería aleccionar y moldear, de cierta manera, la mente de la/el oyente, que en muchos casos es Ana Isabel. Esta niña de 8 años aprende a ver el mundo según las opiniones, los consejos y las órdenes de los mayores a su alrededor.

Otro propósito del trabajo es revelar que, en la muestra, se hallan pocos actos de habla altrocéntricos (destinados a proteger la imagen del otro) precisamente porque Ana Isabel, la oyente/receptora, es una niña a la que están tratando de inculcarle ciertas normas sociales para que encaje con un ideal de clase social. Lo anterior está estrechamente relacionado con los tres sistemas de cortesía aplicados a las normas pragmáticas (observadas en el mundo anglosajón): jerarquía, deferencia y solidaridad ( $c f$.
Scollon y Scollon 2001). Estos tres sistemas pueden observarse en variados contextos, y se basan principalmente en las diferencias de poder $(+\mathrm{P}$ o $-\mathrm{P})$ y distancia $(+\mathrm{D}$ o $-\mathrm{D})$ entre los participantes. Se verá claramente por los ejemplos que a mayor poder, bien sea por estatus socioeconómico o por una supuesta supremacía blanca, y sin importar la distancia, menor cuidado tendrán los hablantes al emitir actos de habla egocéntricos y sin mitigación. Para Bravo (2002), la atenuación (o mitigación) es "una función que adquiere un comportamiento comunicativo en un contexto determinado cuando sirve el objetivo de disminuir el efecto social negativo de una amenaza" (p. 143, énfasis del original). Si los hablantes no "necesitan" proteger su imagen ante la oyente, entonces no se recurrirá a la mitigación.

Para cerrar este apartado, es importante señalar que la teoría de la cortesía de Brown y Levinson (1987) proporciona una buena base para el análisis de los diálogos en Ana Isabel, una niña decente. Haverkate (2001, p. 129), a propósito de su análisis del Quijote, expone que “... la teoría de la cortesía verbal de Brown y Levinson genera una perspectiva pragmática auténtica para valorar la personalidad y los roles sociales de los protagonistas de la novela". En este sentido, pues, su reflexión se adapta también a la novela escogida para el presente trabajo.

\section{Metodología}

Para la realización de este proyecto, se leyó la novela Ana Isabel, una niña decente, de Antonia Palacios (1949), prestando suma atención a los actos de habla que contuvieran alguna alusión directa o indirecta a la raza o la clase social, bien dirigida a los propios hablantes que emitían el acto de habla o bien a otros personajes de la obra. Estos actos de habla se recolectaron a partir de los diálogos de la novela. Se encontraron los siguientes tipos de actos de habla, según la clasificación de Searle (1976) y la distinción entre egocéntrico y altrocéntrico propuesta por Haverkate (2001): 
Universidad Pedagógica Nacional

Facultad de Humanidades

Tabla 1. Descripción y cuantificación de los actos de habla en los diálogos de Ana Isabel, una niña decente, de Antonia Palacios

\begin{tabular}{|c|c|c|c|c|}
\hline \multirow{2}{*}{ Tipo de acto de habla } & \multirow{2}{*}{$\begin{array}{l}\text { Tipo de amenaza a la imagen } \\
\text { en el contexto estudiado }\end{array}$} & \multicolumn{2}{|c|}{ Estado psicológico del hablante } & \multirow{2}{*}{$\begin{array}{c}\text { Total } \\
n\end{array}$} \\
\hline & & Egocéntrico $n$ & Altrocéntrico $n$ & \\
\hline \multirow[t]{2}{*}{$\begin{array}{l}\text { Representativos } \\
\text { (o asertivos): }\end{array}$} & Imagen positiva del oyente & 13 & 1 & \\
\hline & & \multicolumn{2}{|c|}{+1 de doble dimensión $=$} & 15 \\
\hline $\begin{array}{l}\text { Directivos } \\
\text { (o exhortativos): }\end{array}$ & Imagen negativa del oyente & 9 & $0=$ & 9 \\
\hline
\end{tabular}

Posteriormente se realizó el análisis cualitativo de estos datos, el cual se desarrolla en el próximo apartado.

\section{Análisis de los datos}

El siguiente análisis consiste en mostrar el tipo de acto de habla y su interrelación con las variables de raza y clase social. Las subdivisiones se realizaron a partir del tipo de acto de habla, para luego comentar sobre el tipo de amenaza a la imagen y el estado psicológico del hablante (acto egocéntrico o altrocéntrico).

\section{Actos de habla representativos (asertivos)}

Según Bravo (2002), los actos asertivos no guardan características evidenciables, como la petición o las invitaciones, por tanto, son los menos estudiados. Searle ([1969] 1994) explica que "una aseveración es un [género muy especial de] compromiso con la verdad de una proposición" (p. 38). El investigador señala que con este tipo de acto se asevera, enuncia o afirma "cualesquiera proposición de $p$ " (p. 74). Es decir, $H$ cree que $p^{5}$. La condición previa para que esto se dé es que $H$ ha obtenido evidencias o tiene razones para la verdad de $p$. Cuenta como la asunción de que $p$ representa un estado de cosas efectivo. A diferencia de argumentar, estos actos no parecen estar ligados esencialmente a intentar

5 Donde $\mathrm{H}$ se entiende como "Hablante" y $p$ como "proposición" convencer. Sin embargo, no se les puede considerar amenazantes fuera del contexto sociocultural en el cual son expresados. En la novela en cuestión se observa, mayormente, en momentos en que se hace referencia a personas de estatus socioeconómico bajo y de raza negra en los diálogos de la novela de Palacios (1949):

(1) ¡Esa gente del cerro es tan floja! (p. 13).

(2) Esa gente del pueblo, Estefanía, es tan grosera y pueden darle un empujón a los niños y estropear los disfraces (p. 24).

(3) Esos ranchos, Estefanía, donde solo se cogen enfermedades y malas mañas (p. 45).

(4) Esa gentuza que no se sabe de dónde ha salido (p. 85).

(5) ¡Ah la hija de Tula Madriz! Por cierto que Tula se casó muy mal, con un muchacho desconocido un chico del interior... (p. 85).

(6) ¡La sangre de los Alcántara no se mezclará nunca con sangre plebeya! (p. 89).

(7) Un escudo muy limpio tenemos. Y no poseemos dinero, prueba de que no somos ladrones ni pillos... (p. 89).

(8) Sí, juega en la plaza... Pero no es lo mismo. Además, no se sabe quién es su mamá ni su papá (p. 114).

(9) Una negrita que Ana Isabel quería meter para adentro (p. 114). 
(10) ¿Negrita? Pero si Carmencita es blanca (p. 114).

(11) ¡Una catalana! ¡Quién sabe qué clase de gente será ésa! (p. 35)

(12) (...) Te he dicho mil veces que esos dulces son muy cochinos. Tú tienes la culpa de haberte enfermado (p. 117).

(13) ¡Quién sabe si serálechinas lo que tiene esta niña! Y esto le pasa por estar jugando con esos muchachos sucios y andrajosos (p. 117).

(14) Mire niña, no hay más que ricos y pobres. Los ricos pá gozá y los pobres pá aguantá (p. 71).

(15) Imposible, mijita. Temperar es para los ricos. Los pobres estamos condenados a no movernos de aquí... (p. 43).

Los quince tipos de acto de habla expuestos aquí se pueden considerar críticas, y todos hacen referencia específica sectores particulares de la población: la gente negra o la de escasos recursos. La excepción sería el ejemplo (14) ya que, como se discutirá más adelante, en él, la hablante es Estefanía, la sirvienta negra que trabaja para la familia de los Alcántara, y quien emite una crítica también hacia el grupo contrario: la gente con más poder económico y social.

Según la teoría de Brown y Levinson (1987), las críticas, expresiones de desaprobación, desprecio o ridiculización, quejas, reprimendas, acusaciones e insultos pertenecen al tipo de actos que amenazan la imagen positiva del oyente, ya que implican que al hablante no le importan los sentimientos ni los deseos del oyente, así como tampoco le gustan sus acciones, características personales, creencias y valores. Es válido, por tanto, aducir que en los ejemplos encontrados las relaciones de poder son verticales y que la distancia entre ambos interlocutores no cuenta. Sucede esto en los casos en que el hablante posee más poder que el oyente.

El caso (1) es sumamente interesante, puesto que el enunciado lo hace Amelia, un personaje que aparece en esa única ocasión para describir a la gente pobre, del cerro. Lo único que se sabe de ella es que es una mujer que se dedica a llenar latas de agua y subirlas a la "gente del cerro"6. Se presume, por su oficio, que es una mujer humilde, pero se siente en capacidad de emitir una crítica así porque no se ve a sí misma como parte de ese grupo que vive de forma aún más marginalizada, quizá porque ella vive en la ciudad y no en las colinas de sectores extremadamente pobres. En este caso, la hablante emite la crítica frente a un herrero, Ana Isabel (la niña protagonista) y Estefanía, por lo que es posible que esté en busca de solidaridad y confirmación por parte de los oyentes (que también son pobres). El estado psicológico de la hablante parece ser egocéntrico sin mitigación, puesto que potencialmente amenaza la imagen de los oyentes y busca enaltecer la suya con autocortesía.

Las aseveraciones (2) y (3) son hechas por la madre de Ana Isabel, la señora Alcántara, cuya interlocutora en ambos casos es Estefanía, la sirvienta pobre y negra de la familia. Nuevamente, la crítica se dirige a la gente que, desde la visión de los padres de Ana Isabel, es inferior por no tener abolengo. Es obvio que las detracciones son hechas sin ningún tipo de consideración hacia la oyente, por lo que son también egocéntricos. El ejemplo (4), surgido de la voz de la señora Alcántara, aparece en medio de los pensamientos de Ana Isabel acerca de las razas del mundo y sobre cómo en Venezuela hay mucha gente negra y a ella no la dejan jugar con negros; por la voz de el/la narrador(a) se comprende que "En Venezuela hay muchos negros. Los negros no son gente decente" (Palacios, 1949, p. 85). Y continúa explicando que a Ana Isabel no la dejan reunirse con negros ni tampoco con algunos blancos. Es, si se quiere, un recordatorio de lo que su madre le dice para aleccionarla. La palabra "gentuza" abarca también a las personas de clase baja. En este caso, si bien Ana Isabel no es negra, la hablante no tiene en cuenta que la niña tiene amigos de esa raza y de su misma clase social, o sea, baja, aunque la madre insista en separarlos de

6 En varias ciudades de Venezuela, Caracas en particular, es distintivo que, por tratarse de una zona montañosa, los cinturones de miseria se asentaron, desde muy temprano, en las faldas de las montañas, y así se fueron expandiendo hacia la cima. Se entiende que estas personas no viven en casas propiamente dichas, sino en ranchos, que en español de Venezuela significa "Vivienda construida con zinc, cartones, latas, etc. ubicada en la periferia de las ciudades y que sirve como residencia a personas de pocos recursos" (Diccionario de venezolanismos Project Babel). 
la propia porque ellos alguna vez fueron una familia de alcurnia en Caracas. Se ve el mismo caso en (5), cuando la madre afirma que su conocida, a quien señala con nombre y apellido, Tula Madriz, se casó con un donnadie, por ser una persona del interior del país (del campo), sin un apellido famoso. Se perciben dos actos de habla totalmente egocéntricos, sin ningún tipo de mitigación y con agraviamiento.

En los apartados (6) y (7) aparecen unos de los pocos diálogos del señor Alcántara, padre de la protagonista. Estas palabras surgen en medio de las cavilaciones de la niña al pensar en Eusebio, su amigo negro, y cómo, aunque se volviera blanco, ella no podría nunca casarse con él. Sugiere la afirmación del padre que el tema de la raza y la clase son una constante en la casa de los Alcántara, quizá por el temor de ver a sus hijos mezclarse con gente que, a sus ojos, es ordinaria y vulgar, a diferencia de ellos que, aunque no tienen dinero, son muy decentes y de un linaje superior. Se observa claramente la división entre ellos, los pobres decentes, y los otros, los pobres que son "pillos y ladrones". Esta visión concuerda con la de los positivistas, mencionada en líneas anteriores, de que el color de piel era equivalente automático de, al menos, más estatus social. Las duras sentencias del padre de Ana Isabel, claro está, no tienen en cuenta los sentimientos ni la imagen de ella como oyente, por lo que son actos de habla egocéntricos sin mitigación y con agraviamiento.

El ejemplo (8) resulta de la negativa de la señora Rodríguez, madre de Teresita, compañera de clases de Ana Isabel, de permitir que Carmencita, la hija del carbonero, se quede en la fiesta de cumpleaños de su hija. Ana Isabel, quien inocentemente, ha invitado a Carmencita a la fiesta de cumpleaños de Teresita, insiste en recordarle a la señora Rodríguez que Carmencita juega con ellas todas las tardes y su papá es Ruperto, el carbonero. Aun así, y sin importarle los sentimientos de las dos niñas, la señora reconoce que, a pesar de que jueguen juntas, ella no sabe quién es el padre de Carmencita e insiste en que la niña se tiene que ir. Se entiende que este caso es como los tres anteriores, en el sentido de que las personas de alcurnia (bien sea por dinero y descendencia o solo por descendencia) consideran que las que no la tienen, literalmente, no son nadie. A todas luces, se trata de un acto de habla egocéntrico con muy poca mitigación, ya que la Señora Rodríguez emplea el preparador "mijita" (véase el ejemplo 9 del apartado "Actos de habla directivos") como evidencia de cariño a Ana Isabel.

El ejemplo (9), por su parte, es expresado por Luisa Figueroa en respuesta a la pregunta hecha por las demás compañeritas de Ana Isabel. Puede verse este enunciado como un caso de autocortesía, pues la hablante se está demarcando de la referida niña y, de algún modo, se autovalora como superior a ella. Como se recordará, al principio de este trabajo se mencionó que, según la visión de la niña protagonista, Luisa Figueroa es muy trigueña, casi negra, y en el ejemplo (10) Ana Isabel reitera que Carmencita es blanca. Es así como el primero de los dos actos (9) es egocéntrico con agravio explícito, puesto que se insulta no solo a la persona a quien se hace referencia, Carmencita, sino también a Ana Isabel, por haberla traído a la fiesta. El segundo acto (10) también se presenta como un acto egocéntrico con agraviamiento implícito, puesto que Ana Isabel insinúa que Carmencita es blanca y no trigueña como Luisa Figueroa. Nichols (2013) explica que, en tiempos poscoloniales, comenzó a observarse en Venezuela "el blanqueamiento" a través de dinero, estatus social o tierras y de allí que se hiciera popular el dicho "el dinero aclara" (p. 174, mi traducción) ${ }^{7}$. Comenta, además, la autora que "todos los ciudadanos café con leche podían usar su riqueza y poder para reforzar su derecho a tener una posición 'decente"' (p. 174, mi traducción, énfasis del original).

Los ejemplos anteriores conectan con el ejemplo (11), en el que la señora Alcántara expresa un comentario xenofóbico respecto a la familia de Justina, la nueva amiga de Ana Isabel, presumiblemente por una de dos razones: la primera, simple ignorancia por no haber visto jamás gente catalana, o, la segunda, por asociar a los catalanes con inmigrantes pobres que llegaron a Venezuela durante

7 Si bien la traducción de "money whitens" es, literalmente, "el dinero blanquea", el verdadero dicho en Venezuela es "la plata aclara" o "el dinero aclara". Se presume que se debe a que a más dinero, la piel se va percibiendo cada vez más clara o menos negra. 
el siglo xx en busca de un futuro mejor. En ambos casos, se observa el desdén de la madre al exclamar retóricamente " $i Q u i e ́ n$ sabe qué tipo de gente será esa!", afirmación que automáticamente los clasifica como inferiores. Es de hacer notar que Ana Isabel responde a su madre con "Pero si no son negros, mamá" (Palacios, 1949, p. 35), con lo que se observa que la niña ya tiene aprendida la lección de que los negros no son gente de fiar ni tampoco dignos de pertenecer al círculo de amistades de los Alcántara. No existe ningún tipo de mitigación en este caso, y la reacción de Ana Isabel hace suponer que el comentario ha ofendido su imagen positiva, por lo que se considera egocéntrico con agraviamiento.

Los casos (12) y (13) también son enunciados de la madre de Ana Isabel, quien nuevamente profiere afirmaciones que, más que críticas, son ya insultos contra las personas de clase baja y los productos que ingieren. Es así como la madre asegura en (11) que los dulces que Ana Isabel se comió son "muy cochinos" porque fueron hechos por gente desaseada o sucia, aunque la madre no tenga ninguna evidencia de esto, para seguidamente culpar a la niña de sentirse mal, ya que es consecuencia natural de jugar con niños sucios y comer lo que ellos comen. La crítica y la recriminación hacia Ana Isabel es directa, sin mitigación, por lo que se trata de un acto de habla egocéntrico con agraviamiento. Igual se puede decir del enunciado (12): la madre censura a la niña en tercera persona, aunque esté hablando directamente con Ana Isabel. Si bien esto podría verse como un tipo de mitigación, no lo es, ya que la madre insiste en culparla por tener amistades tan indeseables, según su punto de vista.

Seguidamente, el caso (14) es el único acto de habla asertivo altrocéntrico hallado en la muestra. En él se observa cómo Estefanía, la sirvienta negra de la familia de Ana Isabel, intenta responder a sus inquietudes sobre por qué son siempre los pobres los que no son decentes. Al usar el apelativo "niña", la mujer hace una muestra de respeto. Asimismo, minimiza su imagen frente a la de Ana Isabel al decir que el mundo es así y que las personas pobres como ella vinieron al mundo a pasar calamidades, $y$ que la gente como Ana Isabel vino a disfrutar de la vida. La sirvienta no daña la imagen de la niña, sino más bien la propia. En otras palabras, se enaltece la imagen positiva de la oyente.

Por último, el ejemplo (15) también es muy singular, ya que presenta una doble dimensión sicológica: por un lado, apunta a desfavorecer la imagen positiva de la oyente y, por el otro, la de la hablante. Cuando la madre le explica que ni Ana Isabel ni su familia pueden irse de paseo al mar (temperar) porque no tienen dinero y que, como son pobres, están "condenados" a permanecer en un solo lugar toda su vida, está emitiendo un acto de habla representativo que se puede considerar un acto egocéntrico y altrocéntrico al mismo tiempo. Es decir, es egocéntrico porque su madre le está indicando directamente que es una niña pobre, pero al incluirse a sí misma junto con Ana Isabel en el grupo estigmatizado, logra matizar la dureza del acto y lo convierte en altrocéntrico. Además, se observa cierta mitigación a través del vocativo "mijita".

\section{Actos de habla directivos}

Como se dijo, los actos de habla directivos son intentos por parte del hablante de lograr que el oyente haga algo. Brown y Levinson (1987) afirman que estos amenazan la imagen negativa del oyente al indicar, potencialmente, que al hablante no le importa coartar la libertad de acción del oyente. Además, Ferrer y Sánchez Lanza (2002) agregan que los actos de habla exhortativos, que corresponden a los llamados por Searle actos directivos, no siempre requieren una respuesta verbal, pero tienden a suscitar una reacción del interlocutor. Entre las acciones que pertenecen a esta clase se incluyen ordenar, mandar, requerir, pedir y otros. Para estas autoras, desde el ángulo de la intencionalidad, unos actos son más exhortativos que otros, unos tienen más fuerza impositiva que otros. Influye en ello la relación costo-beneficio; en los primeros, el beneficio apunta hacia el que pronuncia el enunciado (mandato, pedido, ruego), mientras que los segundos están encaminados a favorecer a quien los recibe (consejo, recomendación). Se infiere entonces que, en el contexto de esta investigación, los 
actos con más fuerza impositiva, como los mandatos, serán del tipo egocéntrico, y los que son menos impositivos, como los consejos, serán del tipo altrocéntrico.

A continuación, se exponen los ejemplos de actos de habla directivos relacionados con clase social y raza que aparecen en la novela y, posteriormente, se hace un análisis pragmático de los mismos:

(1) Hay que tener cuidado en escoger el material que ha de ser de la mejor calidad (p. 43).

(2) No hay que amar al cuerpo. El cuerpo es castigo del alma (p. 52).

(3) Arréglense para ir a confesarse. A hacer su examen de conciencia (p. 52).

(4) Mire, niña, si me tumba el azafate, no me venga luego con brinquitos (p. 64).

(5) Niñas, no se metan con ese hombre que les puede salir con una grosería (p. 78).

(6) ¡Pero no llores, Ana Isabel! No hay que llorar así por un vestido. No te vayas. ¿Para dónde vas? (p. 41).

(7) Déjate de malacrianzas Ana Isabel. Primero un amor con las vacas y ahora les toma manía. Mira hija, las vacas representan una ayuda para vivir, ya lo sabes. Así es que se quedan aquí (p. 95).

(8) ¿De dónde voy a sacar yo para comprar seis kilos de carne? Si es así no vas a la excursión (p. 73).

(9) Sí, mijita, pero no puede quedarse en la fiesta. No puede, mijita... Cuando seas grande, comprenderás (p. 114).

Los primeros dos enunciados pueden ser vistos como actos de habla exhortativos, es decir, con menos fuerza impositiva que los mandatos. La diferencia entre ellos se puede hallar en que (1) es, sobre todo, un consejo o una recomendación, y (2) apunta más bien hacia la advertencia. Según Searle ([1969] 1994), se ofrece un consejo cuando el hablante cree que cierta acción beneficiará al oyente; y se hace una advertencia cuando el hablante cree que algo no es de interés para el oyente. Es así como en (1), la maestra está charlando con Ana Isabel y sus compañeras de clase sobre la primera comunión y les recomienda ser cuidadosas al escoger la tela del vestido para la ceremonia, sobre todo porque van a tomarla con las chicas del Colegio de las Hermanas, el cual, se presupone, es más costoso; esta circunstancia obliga a las alumnas del colegio de Ana Isabel a guardar las apariencias. El enunciado (2), emitido por un personaje que aparece esa única vez, la tía Clara, es una amonestación hecha a Ana Isabel porque considera que tiene "instintos de mujer mala, mujer de la calle" (Palacios, 1949, p. 52). Esta advertencia también va dirigida a cuidar la pureza, tema directamente asociado con las mujeres de cierta clase social que deben siempre parecer inocentes. Hincapié (2007) a propósito de los ideales femeninos del siglo XIX, afirma que toda mujer que fuera buena, es decir, que cumpliera con las indicaciones de conducta y espiritualidad que se delimitan en los manuales de conducta, era bella, ya que era "inocente, virginal y angelical" (p. 293). Lo que la novela da a entender, entonces, es que dichas normas e ideales se siguieron observando hasta bien entrado el siglo xx, sobre todo entre la clase alta, o por los que querían aparentar ser de alcurnia, o gente "decente". Se infiere que, por tanto, Ana Isabel no podía escapar de la convención.

Se puede decir que el primero de los dos ejemplos es, en apariencia, altrocéntrico, pero resulta siendo egocéntrico sin mitigación, puesto que la maestra no tiene en cuenta la situación económica de Ana Isabel como oyente y expresa principalmente su deseo de que sus alumnas luzcan lo más elegantes posible. El caso (2) es, a todas luces, un acto de habla egocéntrico con agraviamiento, ya que la tía no solo se encarga de expresar sus creencias personales, sino de advertir a Ana Isabel que recibirá un castigo divino si no se ciñe a estas.

Los enunciados (3) a (6) son ejemplos de mandatos u órdenes, por lo que exhiben una mayor fuerza impositiva. Searle ([1969] 1994) explica que un pedido se efectúa si el oyente es capaz de hacer algo, y si no es obvio ni para el hablante ni para el oyente que la acción se vaya a realizar de manera espontánea según el curso normal de los acontecimientos. Sin embargo, asegura el autor que ordenar y mandar tienen la regla preparatoria adicional de que el hablante debe estar en una posición de autoridad sobre el oyente. Así es 
como en (3) la maestra, figura de máxima autoridad en la escuela y para las niñas, las envía a confesarse a pesar de que haya niñas como Ana Isabel que se sientan ansiosas ante todos los procedimientos religiosos que han de seguir antes de recibir la primera comunión. Todos estos preparativos escolares y religiosos son propios solo de los grupos sociales que pueden permitírselos. Entre las clases bajas, quizás no existan estas ceremonias. Al no tomar en consideración los deseos de la(s) oyente(s), este acto se convierte en egocéntrico sin mitigación.

El número (4) es también muy interesante, ya que es un mandato que le hace Estefanía, la sirvienta de la casa, a Ana Isabel. Este caso revela, nuevamente, que pareciera que los hablantes, incluso los que son de menor posición social, no tienen en cuenta la imagen de Ana Isabel por ser una niña. En teoría, la pequeña es una figura de autoridad frente a Estefanía, porque esta trabaja para su familia, pero en la práctica, la sirvienta tiene más poder sobre ella cuando no están los padres alrededor. Este acto de habla puede considerarse un mandato con la función pragmática de advertencia: si la niña no obedece, deberá atenerse a las consecuencias. Ya se ha observado que la forma del acto de habla directivo puede asociarse a una petición, pero además puede acarrear un acto de habla primario expresado con mecanismos tales que cumplan funciones pragmáticas distintas a las de ordenar, pedir, sugerir, rogar, etc. ( $c f$. Magdaleno y Gutiérrez-Rivas, 2013). Es así como esta advertencia que se realiza en forma de mandato es un acto egocéntrico, puesto que la empleada está amenazando a la niña con consecuencias graves si no hace lo que se le ordena.

En el caso (5), la maestra se dirige a las niñas durante un paseo, ya que estas le han gritado a un arriero que no le pegue a su burro. No queda claro si todavía la hablante está frente al arriero cuando emite el mandato, pero de ser así, la maestra no tiene en cuenta ni la imagen negativa de las niñas (a quienes no respalda en su decisión de imponerse al maltrato del hombre), ni la del hombre, que es un perfecto desconocido y de quien insinúa que es un hombre rudo y, potencialmente, vulgar. Es, entonces, un acto de habla egocéntrico con agraviamiento. La maestra está enalteciendo su propia imagen como mujer educada frente a una persona del campo, a la que considera bruta y maleducada.

En (6), la madre le exige a su hija que no llore, ante la frustración de Ana Isabel por no poder tener un vestido como el que la maestra sugiere. La señora explícitamente le dice que "ese traje cuesta mucho dinero y nosotros somos muy pobres" (Palacios, 1949, p. 41). De nuevo, es un acto de habla egocéntrico al imponerse sobre los sentimientos y acciones de la oyente. Un caso muy parecido sucede en (7), cuando la madre le reclama a su hija que sea tan malcriada y le exige cesar con ese comportamiento. En este caso, a pesar de tratarse de un acto egocéntrico, la madre ofrece una explicación que sirve como atenuante o mitigador del fuerte mandato: "Las vacas representan una ayuda para vivir” (Palacios, 1949, p. 95).

Finalmente, se han incluido los apartados (8) y (9) como parte de los actos de habla directivos aunque funjan, más específicamente, como negativas a pedidos. El ejemplo (8) se divide entre una pregunta retórica, que sirve a su vez como un acto preparador antes de la negativa. Cuando la madre pregunta “De dónde voy a sacar yo para comprar seis kilos de carne?", en realidad le está dando a entender a Ana Isabel que lo que exige su maestra es irracional, por lo que, acto seguido, le explica que, si esa es la condición para ir de excursión con las chicas del colegio, la decisión es que ella no irá. Se observa que el acto es egocéntrico, ya que no toma en consideración la opinión de la niña y no solo coarta su libertad de acción, por pequeña que sea, ya que se trata de una menor, sino que, además, no le da espacio para hacer preguntas o réplicas. El enunciado (9) aparece, justamente, después de una réplica de Ana Isabel a la señora Rodríguez, la madre de Teresita, la niña que celebraba su fiesta de cumpleaños. Luego de explicarle que sí se sabe quiénes son los padres de Carmencita, con la esperanza de que la señora permita que su amiguita se quede en la fiesta, la dueña de la casa le dice a Ana Isabel que reconoce que ella tiene razón, pero aun así Carmencita no se puede quedar y Ana Isabel tendrá que decirle que se vaya. Agrega la dama una sentencia final: "Cuando seas grande, compren- 
derás", con la que intenta mitigar la negativa al pedido de la pequeña. Aun así su enunciado es totalmente egocéntrico, puesto que se trata de un hecho que podría ocurrir o no en un futuro remoto.

\section{Conclusión}

Delimitar el marco teórico de esta investigación y realizar el subsecuente análisis pragmático presentó dos retos significativos. El primero fue hallar dos teorías complementarias que pudieran explicar los tipos de actos de habla relacionados con raza y clase social presentes en la novela. El segundo, intentar articular la dimensión sicológica de los hablantes en referencia a la amenaza del oyente. La solución a ambos desafíos se halló al combinar la teoría de los actos de habla de Searle ([1969] 1994) con la teoría de la cortesía de Brown y Levinson (1987). El segundo desafío, en particular, halló solución al aplicar los conceptos de actos de habla egocéntricos y altrocéntricos de Haverkate (2001) a los ejemplos encontrados para, por medio de un cuidadoso análisis, dilucidar si existía o no mitigación y, por consiguiente, menor amenaza a la imagen, en los actos egocéntricos.

En general, se determinó que los actos representativos (o asertivos) y directivos (o exhortativos) examinados que, en particular, hacen referencia a clase social y raza, son en su mayoría egocéntricos sin mitigación, por lo cual se convierten en descorteses y se separan de lo que propone Haverkate (2001) en cuanto a la mitigación como acompañante del acto de habla egocéntrico. Se pueden hacer ciertas conjeturas con respecto a lo hallado. Por ejemplo, con respecto a la mitigación, Briz (2003) señala que, en situaciones despreferidas o poco cooperativas, como una crítica al interlocutor o a alguien cercano a este, la función cortés de los atenuantes (o mitigadores) es evidente y además se cumple el principio que parece soportar dicha actividad: la búsqueda de lo que Hernández -Flores (2002) llama el equilibrio de imágenes. Entonces, ¿qué induce a los personajes a expresar sus convicciones y dar órdenes sin ningún tipo de mitigación y, lo que es más, con matices de descortesía? Presumiblemente, la razón se halla en la baja relación costo-beneficio ya mencionada. Según Ferrer y Sánchez Lanza (2002), el grado de exhortación e imposición de los actos de habla dependerá de dicha relación costo-beneficio. Por tanto, se entiende que los hablantes que ostenten una posición de autoridad, mayor estatus social, o se consideren de cierta superioridad étnica o racial no dan mucho peso al grado de imposición de sus mandatos, pedidos e incluso, recomendaciones. Además, se ven a sí mismos en una posición de privilegio tal que también expresan sus creencias, por racistas, clasistas o xenofóbicas que sean, de una manera más desinhibida.

Por último, otro factor importante es el hecho de que la oyente en casi todos los casos es Ana Isabel, una niña de ocho años sin poder alguno en un mundo de adultos o de compañeras de estudio con mayor posición social que ella. Este ingrediente anima a los interlocutores a no sentir la necesidad de cuidar la imagen positiva de la oyente, en caso de expresar sus creencias, ni tampoco su imagen negativa, al emitir mandatos, puesto que la oyente no tiene ningún poder sobre ellos.

Igualmente, se observa el elemento descortés del agraviamiento para imprimir más autoridad a lo que se le dice a la niña y hacer que sucumba a las creencias y órdenes de los interlocutores. Lo mismo ocurre cuando hay otros oyentes presentes que no tienen poder sobre los hablantes, como Estefanía, la sirvienta negra de la casa. En estos casos, no solo el poder sino la distancia entre empleada y patrona le da carta blanca a esta para agraviar la imagen de la mujer de color y clase baja. Es importante recordar que hay dos interacciones en que otra niña agravia a Ana Isabel (ejemplo 9, apartado "Actos de habla representativos"), pero la diferencia está en que, aunque las dos sean menores de edad y compañeras de clase, la niña que comete el agravio es de una clase social superior. El paralelismo es evidente en el ejemplo en que la madre de Ana Isabel denigra de los pobres y las personas de color frente a Estefanía, dado que ella misma también es pobre. El único rasgo de superioridad que puede ostentar es, entonces, el de la piel blanca.

Lo hallado en esta investigación se adhiere a lo comentado sobre la evolución histórica y la percepción de raza y clase social en Venezuela en la primera 
mitad del siglo xx que persiste hasta la época actual. Aún hoy en día, en el imaginario sociocultural venezolano ser blanco es sinónimo de ser superior y de clase pudiente, aunque, como se ve explícito en la novela, esta correlación no siempre se cumple. Por el contrario, el dinero puede "blanquear" a una persona oscura, y la piel clara puede hacer sentir a un pobre como alguien superior, es decir, como alguien "decente". Estas variables, sin duda, afectan el comportamiento lingüístico de los hablantes y es esto, precisamente, lo que se ve reflejado en la novela Ana Isabel, una niña decente.

Futuros análisis podrían servirse de comparaciones entre novelas de valor histórico y novelas contemporáneas, o del lenguaje natural versus el literario.

\section{Referencias}

Álvarez, A. y Valeri, M. J. (2005). Imagen y cortesía en Ifigenia, de Teresa de la Parra. Lengua y Habla, 9(1), 9-26.

Austin, J. (1962). How to do things with words. Oxford: Oxford University Press.

Beals, R. L. (1953). Social stratification in Latin America. American Journal of Sociology, 58(4), 327-339.

Bidot Martínez, I. y Vargas Arias, I. (2012). El Insulto en La Obra "Aire Frío" De Virgilio Piñera. Logos: Revista de Lingüística, Filosofía y Literatura, 22(1), 14-33.

Bolívar, A., Chollett, M. B., Bisbe, L., Briceño-León, R., Ishibashi, J., Kaplan, N. y Velásquez, R. (2007). Discurso y racismo en Venezuela: un país café con leche. En T. A. van Dijk (ed.). Racismo y discurso en América Latina (pp. 371-423). España: Gedisa.

Bousfield, D. (2008). Impoliteness in interaction (vol. 167). Amsterdam: John Benjamins Publishing.

Bravo, D. (2002). Actos asertivos y cortesía: imagen del rol en el discurso de académicos argentinos. En M.E. Placencia y D. Bravo (eds.). Actos de habla y cortesía en español (pp. 141-174). Lincom Europa.

Bravo, V. (2008). Libros clave de la narrativa venezolana I. Ana Isabel, una niña decente. Rinconete. Centro Virtual Cervantes. Recuperado de http://cvc.cervantes.es/ el_rinconete/anteriores/marzo_08/07032008_02.htm

Briz, A. (2003). La estrategia atenuadora en la conversación cotidiana española. En D. Bravo (ed.). Actas del I coloquio del programa Edice. La perspectiva no etnocentrista de la cortesía: identidad sociocultural de las comunidades hispanohablantes (pp. 17-46). Estocolmo: Universidad de Estocolmo.

Brown, P. y Levinson, S. (1987). Politeness. Some universals in language usage. Cambridge: Cambridge University Press.

Brown, R. y Gilman, A. (1989). Politeness theory and Shakespeare's four major tragedies. Language in Society, 18(02), 159-212.

Capriles, C. (2011). Discrimíname. Noticiero Digital. Párrafo 3. Recuperado de http://www.noticierodigital. com/forum/viewtopic.php?t=799119

Castañeda Castañeda, A. Y. (2010). Interacción narradorlector implícito a partir del modelo de cortesía positiva de Brown y Levinson. Tonos Digital, 20, 1-15.

Culpeper, J. (2011). Impoliteness. Cambridge: John Wiley \& Sons.

Diccionario de venezolanismos. Projet Babel. Recuperado de http://projetbabel.org/internet/venezonalismos. htm

Fairclough, N. (1995). Critical discourse analysis: The critical study of language. Londres: Longman.

Ferrer, M. C. y Sánchez Lanza, C. (2002). Interacción verbal. Los actos de habla. Rosario, Argentina: Editorial de Universidad Nacional de Rosario.

Flores Ohlson, L. (2014). Los fenómenos lingüísticos que caracterizan a las protagonistas de Diez mujeres de Marcela Serrano. Lingüistica y Literatura, 66, 15-37.

Fraser, B. (1980). Conversational mitigation. Journal of Pragmatics, 4, 341-350.

Gancedo Ruiz, M. (2016). El texto dramático literario como corpus para el análisis histórico de las actividades de imagen. Textos en Proceso, 2(1), 162-173.

Goffman, E. (1967). On face-work. An analysis of ritual elements in social interaction. En E. Goffman (ed.). Interaction ritual: Essays on face to face behavior (pp. 5-45). Nueva York: Doubleday Anchor.

Gulbas, L. (2008). Cosmetic surgery and the politics of race, class, and gender in Caracas, Venezuela (tesis inédita de doctorado). Southern Methodist University, Estados Unidos.

Gumperz, J. y Hymes, D. (1972) (ed.) Directions in sociolinguistics; the ethnography of communication. Nueva York: Holt, Reinehart y Winston. 
Haverkate, H. (2001). Cortesía y descortesía en los diálogos del Quijote: análisis de la representación de las imágenes positiva y negativa de los protagonistas. Oralia, 4, 129-148.

Hernández Flores, N. (2002). La cortesía en la conversación española de familiares y amigos; la búsqueda del equilibrio entre la imagen del hablante y la imagen del destinatario. Aalborg: Institut for Sprog Internationale Kurturstudier, Aalborg Universitet, vol. 37.

Hernández-Flores, N. (2008). Cortesía y otros tipos de actividades de imagen: significado comunicativo y social en un debate televisivo. Pragmatics, 18(4), 681-707.

Hincapié, L. (2007). “Virgen, ángel, flor y debilidad: paradigmas de la imagen de la mujer en la literatura colombiana de finales del siglo xix". Tabula Rasa, enero-junio (006), 287-307.

Instituto Nacional de Estadística. XIV Censo Nacional de Población y Vivienda. Cuestionario general. Recuperado de http://www.ine.gov.ve/documentos/ Demografia/CensodePoblacionyVivienda/pdf/ Cuestionario_Censo_2011.pdf

Magdaleno, N., y Gutiérrez-Rivas, C. (2013). Funciones pragmáticas de la petición en los comentarios del público a una noticia periodística virtual. Íkala,18(1), 19.

Mey, J. (2001). Pragmatics. An introduction. Malden, MA: Blackwell.

Nichols, E. G. y Morse K. J. (2010). Venezuela. Santa Barbara: ABC-Clio.

Nichols, E. G. (2013). 'Decent girls with good hair': Beauty, morality and race in Venezuela. Feminist Theory, 14(2), 171-185.

Owen, M. (1981). Conversational units and the use of "well..." En P. Werth. (ed.). Conversation and Discourse (pp. 99-116). Nueva York: St Martin's Press.

Palacios, A. (1949 [2004]). Ana Isabel, una niña decente. Buchivacoa: Caracas.
Rivas, L.M. (2010). De Ana Teresa a Ana Teresa: Teresa de la Parra, paradigma de un siglo. Revista Venezolana de Estudios de la Mujer, 15(34), 201-216.

Sacks, H., Schegloff, E. A. y Jefferson, G. (1978). "A simplest systematics for the organization of turn taking for conversation". En J. Schenkein (ed.). Studies in the organization of the conversational interaction (pp. 1-55). Nueva York: Academic.

Schmid, N. J. (2015). Una niña decente... ¿ e inocente?: La intersección de clase y raza en Ana Isabel, una niña decente de Antonia Palacios. Scholarly Horizons: University of Minnesota, Morris Undergraduate Journal, 2(2), 1-26.

Scollon, R.; y Scollon, S. (2001). Intercultural Communication: A Discourse Approach. Malden, MA: Blackwell.

Searle ([1969] 1994). Actos de habla: ensayo de filosofía del lenguaje. Barcelona: Planeta-De Agostini.

Searle, J. (1969). Speech acts: An essay in the philosophy of language. Cambridge: Cambridge University Press.

Searle, J. R. (1976). A classification of illocutionary acts. Language in Society, 5(01), 1-23.

Vallejo Zapata, V. J. (2011). El reproche y el silencio vistos a la luz de la teoría de la cortesía: análisis pragmalingüístico de Diatriba de amor contra un hombre sentado de Gabriel García Márquez. Íkala, 16(29), 45-65.

van Dijk, T. (1998). Ideología. Barcelona: Gedisa.

Venezuela tiene 28.946.101 habitantes. Correo del Orinoco.

Recuperado de http://www.correodelorinoco.gob.ve/ tema-dia/censo-2011-venezuela-tiene-28-946-101-habitantes/

Zamora, F. J. (2014). Actividades de imagen en textos narrativos (ficción y no ficción). Sociocultural Pragmatics, 2(1), 76-115.

Para citar este artículo

Gutiérrez-Rivas, C. (2018). Actos de habla egocéntricos y altrocéntricos y su relación con raza y clase social: un ejemplo en la obra literaria venezolana. Folios, 47, 19-36. 